\title{
Epidemiology of geriatric trauma in United Arab Emirates
}

\author{
Shehabeldin H. Adam ${ }^{a}$, Hani O. Eid ${ }^{a}$, Peter Barss ${ }^{b}$, \\ Karl Lunsjo ${ }^{\mathrm{a}}$, Michal Grivna ${ }^{\mathrm{b}}$, Fawaz Chikh Torab ${ }^{\mathrm{a}}$, \\ Fikri M. Abu-Zidan ${ }^{\mathrm{a}, *}$ \\ ${ }^{a}$ Trauma Group, Department of Surgery, Faculty of Medicine and Health Sciences, \\ United Arab Emirates University, PO Box 17666, Al-Ain, United Arab Emirates \\ ${ }^{\mathrm{b}}$ Trauma Group, Department of Community Medicine, Faculty of Medicine and Health Sciences, \\ United Arab Emirates University, PO Box 17666, Al-Ain, United Arab Emirates
}

Received 27 June 2007; received in revised form 26 August 2007; accepted 29 August 2007

Available online 23 October 2007

\begin{abstract}
The mechanisms and outcome of trauma in hospitalized elderly patients were studied. The data of Al-Ain Hospital Trauma Registry were prospectively collected over a period of 3 years (2003-2006). All elderly trauma-patients above 60 years who were admitted to surgical ward or who died on arrival were studied. Demography of patients, mechanism of injury, Injury Severity Score (ISS), hospital stay and mortality were analyzed. There were 121 patients ( 70 males and 51 females). Mean (range) age was 69 years (60-100), 42\% were United Arab Emirates (UAE) nationals. The two most common mechanisms of injury were falls (55\%) followed by road traffic collisions (RTC) (32\%). The median (range) ISS of the group was 5 (1-34). The ISS median (interquartile range) of falling down, RTC, and fall from height were 4 (4-9), $6(4-10)$, and 8 (5-9), respectively $(p=0.31)$. Forty-one percentage of injuries occurred at home. The mean (range) hospital stay was 12.4 (1-150) days. Six patients $(5 \%)$ were admitted to the intensive care unit. Overall mortality was $6 \%$ (7 patients), of whom 5 were pedestrians hit by cars. We concluded that low-energy trauma from falls was the most common cause of injury in the elderly. Mortality was high mainly from pedestrian injuries.
\end{abstract}

(C) 2007 Elsevier Ireland Ltd. All rights reserved.

Keywords: Trauma in elderly; Traumatic injuries; Mortality

* Corresponding author. Tel.: +971 37137 579; fax: +971 37672067.
E-mail address: fabuzidan@uaeu.ac.ae (F.M. Abu-Zidan).

0167-4943/\$ - see front matter (C) 2007 Elsevier Ireland Ltd. All rights reserved.

doi:10.1016/j.archger.2007.08.018 


\section{Introduction}

The elderly population in UAE is growing (UAE Ministry of Health, 2004). This is attributed to improvements in lifestyle and health care (Margolis et al., 2003). Elderly trauma patients constitute a large part of trauma patients and consume tremendous health care resources (Stevens et al., 2006); having a cost of almost triple that of young patients, (Kauder et al., 2004). Falls remain the most common type of injury in old age (Nagurney et al., 1998; Sterling et al., 2001; Zautcke et al., 2002). Seventy percent of deaths from falls occur in elderly (Kauder et al., 2004). The second common external cause of injury is RTC (Nagurney et al., 1998). Pedestrian vehicle collisions (PVC) have high case fatality ratio in old age (McMahon et al., 1996; Ferrera et al., 2000; Akkose Aydin et al., 2006). The low physiological reserve and the presence of co-morbidities in older patients modify their trauma response as compared to young patients (McMahon et al., 1996; Ferrera et al., 1999; Sterling et al., 2001). Al-Ain Hospital is one of the two main trauma hospitals for Al-Ain City, which has a population of about 400,000 (UAE Ministry of Health, 2004). This study aimed to analyze the external causes and outcomes of hospitalized trauma elderly patients in Al-Ain Hospital, so as to give recommendations on ways to prevent injuries and improve their care.

\section{Methods}

Data of the Trauma Registry of Al-Ain Hospital were collected prospectively over 3 years form March 2003 to March 2006. Patients older than 60 years, who have stayed on surgical wards for more than $24 \mathrm{~h}$, died in Emergency Department or died after admission, were included in the registry.

Data were collected by junior doctors working as Research Assistants and entered using the MS office access. Study variables included: demographics, external cause of injury, nature of injuries, duration of stay and outcomes. AIS coding and ISS calculation of injuries were done manually. Data were analyzed with the Statistical Package for the Social Sciences (version 14, SPSS Inc., Chicago, IL, USA). Kruskall-Wallis test was used to compare ordered data for more than two groups. Fisher's exact test was used to compare categorical data. A $p<0.05$ was considered as significant.

\section{Results}

There were 121 patients, 70 males and 51 females of whom $65 \%$ (79) were $\geq 65$ years. Mean (range) age was 69 years (60-100) and UAE nationals made up $42.1 \%$ (51) of the study population (Table 1). Table 2 shows the external cause of injury. The two most common were falls in the same level 55\% followed by RTCs, 32\%. Falls amounted for $84 \%$ of injuries in females and $34 \%$ among males. RTC victims included 12 pedestrians, 11 drivers, 7 front seat and 2 back seat passengers. Other external causes of injury included 2 patients injured by heavy objects, 2 by animals, 1 by machinery and 1 unknown. Table 3 shows the distribution of injured body regions by external cause. Head, face, chest and 
Table 1

Nationality of hospitalized and fatal cases of injury among patients $\geq 60$ years old in Al-Ain, UAE (2003-2006)

\begin{tabular}{lcr}
\hline Nationality & Number & $\%$ \\
\hline UAE & 51 & 42 \\
Pakistan & 14 & 12 \\
Oman & 12 & 10 \\
Yemen & 6 & 5 \\
Egypt & 6 & 5 \\
Others & 32 & 26 \\
Total & 121 & 100 \\
\hline
\end{tabular}

Table 2

External causes of hospitalized and fatal cases of injuries among patients $\geq 60$ years of age, Al-Ain, UAE (20032006)

\begin{tabular}{|c|c|c|}
\hline External cause of injury & Number & $\%$ \\
\hline Fall & 74 & 61 \\
\hline Same level & 67 & 55 \\
\hline From height & 7 & 6 \\
\hline RTCs & 39 & 32 \\
\hline Burn & 2 & 2 \\
\hline Others $^{\mathrm{a}}$ & 6 & 5 \\
\hline Total & 121 & 100 \\
\hline
\end{tabular}

${ }^{a}$ Other external cause of injury included two patients injured by heavy objects, two by animals, one by machinery and 1 unknown.

Table 3

Distribution of injuries by external cause of hospitalized and fatal cases of injuries among patients $\geq 60$ years of age, Al-Ain, UAE (2003-2006)

\begin{tabular}{|c|c|c|c|c|c|c|c|}
\hline \multirow[t]{2}{*}{ Region } & \multicolumn{2}{|c|}{$\begin{array}{l}\text { Fall on the } \\
\text { same level } \\
(n=67)(59 \%)\end{array}$} & \multicolumn{2}{|c|}{$\begin{array}{l}\text { Road traffic } \\
\text { collision } \\
(n=39)(35 \%)\end{array}$} & \multicolumn{2}{|c|}{$\begin{array}{l}\text { Fall from } \\
\text { height } \\
(n=7)(6 \%)\end{array}$} & \multirow[t]{2}{*}{$p^{\mathrm{a}}$} \\
\hline & $n$ & $\%$ & $n$ & $\%$ & $n$ & $\%$ & \\
\hline Head & 6 & 9 & 14 & 36 & 0 & 0 & 0.001 \\
\hline Face & 2 & 3 & 10 & 26 & 1 & 14 & 0.002 \\
\hline Neck & 0 & 0 & 1 & 3 & 0 & 0 & 0.41 \\
\hline Chest & 11 & 16 & 19 & 49 & 1 & 14 & 0.001 \\
\hline Pelvis and abdomen & 1 & 1 & 0 & 0 & 0 & 0 & 1 \\
\hline Spine & 6 & 9 & 8 & 21 & 3 & 43 & 0.03 \\
\hline Upper limbs & 5 & 7 & 14 & 36 & 3 & 43 & 0.0001 \\
\hline Lower limbs & 40 & 60 & 10 & 26 & 5 & 71 & 0.001 \\
\hline
\end{tabular}

\footnotetext{
${ }^{\mathrm{a}} p=$ Fisher's exact test.
} 
upper limbs were frequent in RTC. Fifty-eight percent of lower limb injuries sustained by falls on the same level were fractured neck of femur. Spine, upper limbs and lower limb injuries were most frequent in fall from height.

Home was the most common location of trauma $41 \%$ (50), followed by streets and highway 32\% (39), then work 7\% (9), off road 4\% (5), farm 3\% (4) and in 12\% (14) the location was unknown. Seventy-two percent of falls on the same level occurred at home, while $71 \%$ of falls from height occurred at work. The median (range) ISS of the patients was 5 (1-34). The ISS median (interquartile range) of falling on the same level, RTC and fall from height were 4 (4-9), 6 (4-10), and 8 (5-9), respectively. ISS was not significantly different between these three external causes ( $p=0.31$, Kruskal-Wallis test). The mean (range) hospital stay was 12.4 (1-150) days. Five percent (6) were admitted to the ICU, of whom three had been injured by RTC, two by falls on the same level, and one by burn. Six percent (7) patients died; five had pedestrian injury, one had a burn and one was a motorcyclist. Two died in the ICU and five died in Accident and Emergency department. Five of seven patients who died were males.

\section{Discussion and conclusion}

Falls are the most common mechanism of injury in geriatric trauma (Sterling et al., 2001), and falling down while standing or walking is common in old age (Nagurney et al., 1998; Ferrera et al., 2000; Sterling et al., 2001; Ghodsi et al., 2003; Bergeron et al., 2006). This is similar to our findings. In our study, home was the most common location for falling down and females were more frequently injured by falls than males.

Low falls can cause severe life threatening injuries (Helling et al., 1999). Head, extremities and chest have been reported to be the most injured regions in old age (Ferrera et al., 1999; Kannus et al., 2005; Akkose Aydin et al., 2006) which is similar to our findings. Fractured neck of femur was the most common injury after falling down in our study. This is attributed to osteoporotic changes in old age. Fall injuries have been shown to have a higher cost in women than men because of fractures sustained in osteoporotic women (Stevens et al., 2006).

Elderly patients are more affected by trauma compared with young patients because of their reduced physiological reserve. This leads to a higher risk of hypotension, hypovolemia, hypoglycemia and syncope (McMahon et al., 1996). Falls in old age cause higher ISS compared with young age (Sterling et al., 2001). Co-morbidity has a major effect on trauma outcome (Ferrera et al., 1999; Bergeron et al., 2006).

The majority of death in our study was in pedestrian injuries. This is similar to other studies (Ferrera et al., 2000; Akkose Aydin et al., 2006). Our in-hospital mortality (6\%) is relatively lower than other reported geriatric trauma (15-30\%) (Kauder et al., 2004). This may be explained by the high prehospital mortality in developing countries (Arreola-Risa et al., 1995).

The management cost of elderly trauma patients is high. Most of the cost is due to length of hospital stay and ICU care which is related to the presence of co-morbidity and non-fatal fractures (McMahon et al., 1996; Stevens et al., 2006). The mean hospital stay of 12 days in 
our elderly patients is much higher than our overall mean hospital stay of (6 days) for all trauma patients in our trauma registry.

Prevention of geriatric trauma could be achieved by identifying risk factors and acting on them. It has been shown that risk factors identification was not regularly practiced by the Emergency Department physicians in the management of geriatric trauma (Kalula et al., 2006). Actions include educational programs, exercise, removing hazards and obstacles from elderly environment (NICE, 2004). Helmets and hip protectors have been suggested in elderly with high risk of falls (Kannus et al., 2005), but this may not be accepted by elderly in our community who highly value their traditional covering of their heads as a sign of respect.

In summary, we have shown that low-energy trauma (falls on the same level) was the most common cause of trauma in the elderly in Al-Ain city and that mortality was mainly from pedestrian injuries.

\section{Acknowledgements}

This study was supported by Individual University Grant (\# 01-07-8-11/03), Faculty of Medicine Research Grants (NP/03/11, 2003; and NP/04/28, 2004) and an Interdisciplinary Grant (\#02-07-8-1/4).

\section{References}

Akkose Aydin, S., Bulut, M., Fedakar, R., Ozgurer, A., Ozdemir, F., 2006. Trauma in the elderly patients in Bursa. Ulus Travma Derg (Turk. J. Trauma Emerg. Surg.) 12, 230-234.

Arreola-Risa, C., Mock, C.N., Padilla, D., Cavazos, L., Maier, R.V., Jurkovich, G.J., 1995. Trauma care systems in urban Latin America: the priorities should be prehospital and emergency room management. J. Trauma 39, 457-462.

Bergeron, E., Clement, J., Lavoie, A., Ratte, S., Bamvita, J.M., Aumont, F., Clas, D., 2006. A simple fall in the elderly: not so simple. J. Trauma 60, 268-273.

Ferrera, P.C., Bartfield, J.M., D’Andrea, C.C., 1999. Geriatric trauma: outcomes of elderly patients discharged from the ED. Am. J. Emerg. Med. 17, 629-632.

Ferrera, P.C., Bartfield, J.M., D'Andrea, C.C., 2000. Outcomes of admitted geriatric trauma victims. Am. J. Emerg. Med. 18, 575-580.

Ghodsi, S.M., Roudsari, B.S., Abdollahi, M., Shadman, M., 2003. Fall-related injuries in the elderly in Tehran. Injury 34, 809-814.

Helling, T.S., Watkins, M., Evans, L.L., Nelson, P.W., Shook, J.W., Van Way, C.W., 1999. Low falls: an underappreciated mechanism of injury. J. Trauma 46, 453-456.

Kalula, S.Z., De Villiers, L., Ross, K., Ferreira, M., 2006. Management of older patients presenting after a fall. An accident and emergency department audit. S.A. Med. J. 96, 718-721.

Kannus, P., Sievanen, H., Palvanen, M., Jarvinen, T., Parkkari, J., 2005. Prevention of falls and consequent injuries in elderly people. Lancet $366,1885-1893$.

Kauder, D.R., Schwab, C.W., Shaprio, M.B., 2004. Geriatric trauma: patterns, care, and outcomes. In: Mattox, K.L., Feliciano, D.V., Moore, E.E. (Eds.), Trauma. McGraw-Hill, New York, pp. 1041-1053.

Margolis, S.A., Carter, T., Dunn, E.V., Reed, R.L., 2003. The health status of community based elderly in the United Arab Emirates. Arch. Gerontol. Geriatr. 37, 1-12.

McMahon, D.J., Schwab, C.W., Kauder, D., 1996. Comorbidity and the elderly trauma patient. World J. Surg. 8, 1113-1139. 
Nagurney, J.T., Borczuk, P., Thomas, S.H., 1998. Elderly patients with closed head trauma after a fall: mechanisms and outcomes. J. Emerg. Med. 16, 709-713.

NICE (National Institute for Clinical Excellence), 2004. Clinical Guideline 21: Falls: The Assessment and Prevention of Falls in Older People. National Institute for Clinical Excellence, London http://www.nice. org.uk/pdf/CG021NICEguideline.pdf (accessed: 11.1.2007).

Sterling, D.A., O’Connor, J.A., Bonadies, J., 2001. Geriatric falls: injury severity is high and disproportionate to mechanism. J. Trauma 50, 116-119.

Stevens, J.A., Corso, P.S., Finkelstein, E.A., Miller, T.R., 2006. The costs of fatal and non-fatal falls among older adults. Inj. Prevent. 12, 290-295.

United Arab Emirates (UAE), 2004. Ministry of Health. The Statistical Report of 2004. http://www.moh.gov.ae/ mohsite/stat_plan/StatRep2004/images/pdf/008.pdf (accessed 19/02/2007).

Zautcke, J.L., Coker S.B.Jr., Morris, R.W., Stein-Spencer, L., 2002. Geriatric trauma in the State of Illinois: substance use and injury patterns. Am. J. Emerg. Med. 20, 14-17. 